\title{
Potential Therapeutic Strategy in Chronic Obstructive Pulmonary Disease Using Pioglitazone-Augmented Wharton's Jelly- Derived Mesenchymal Stem Cells
}

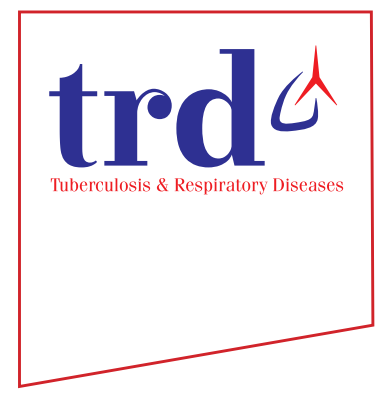

\author{
Jin-Soo Park, Ph.D. ${ }^{1, *(i)}$, Hyun Kuk Kim, M.D. ${ }^{2, *}$, Eun-Young Kang, M.S. ${ }^{1}$, RyeonJin Cho, M.S. ${ }^{1}$ and \\ Yeon-Mok Oh, M.D., Ph.D. ${ }^{1,3,4}$ (i) \\ ${ }^{1}$ Asan Institute for Life Sciences, Seoul, ${ }^{2}$ Division of Pulmonary and Critical Care Medicine, Department of Internal Medicine, \\ Inje University Haeundae Paik Hospital, Busan, ${ }^{3}$ Department of Pulmonary and Critical Care Medicine, University of Ulsan \\ College of Medicine, Seoul, ${ }^{4}$ Department of Pulmonary and Critical Care Medicine, Asan Medical Center, Seoul, Korea
}

Background: A recent study reported that mesenchymal stem cells possess potential cellular therapeutic properties for treating patients with chronic obstructive pulmonary disease, which is characterized by emphysema. We examined the potential therapeutic effect of Wharton's Jelly-derived mesenchymal stem cells (WJMSCs), following pretreatment with pioglitazone, in lung regeneration mouse emphysema models.

Methods: We used two mouse emphysema models, an elastase-induced model and a cigarette smoke-induced model. We intravenously injected WJMSCs $\left(1 \times 10^{4} /\right.$ mouse) to mice, pretreated or not, with pioglitazone for 7 days. We measured the emphysema severity by mean linear intercepts (MLI) analysis using lung histology.

Results: Pioglitazone pretreated WJMSCs (pioWJMSCs) were associated with greater lung regeneration than nonaugmented WJMSCs in the two mouse emphysema models. In the elastase-induced emphysema model, the MLIs were $59.02 \pm 2.42 \mu \mathrm{m}(\mathrm{n}=6), 72.80 \pm 2.87 \mu \mathrm{m}(\mathrm{n}=6)$, for pioWJMSCs injected mice, and non-augmented WJMSCs injected mice, respectively ( $\mathrm{p}<0.01)$. Both pioWJMSCs and non-augmented WJMSCs showed regenerative effects in the cigarette smoke emphysema model (MLIs were $41.25 \pm 0.98$ [n=6] for WJMSCs and38.97 $\pm 0.61 \mu \mathrm{m}[\mathrm{n}=6]$ for pioWJMSCs) compared to smoking control mice $(51.65 \pm 1.36 \mu \mathrm{m}, \mathrm{n}=6)$. The mean improvement of MLI appeared numerically better in pioWJMSCs than in non-augmented WJMSCs injected mice, but the difference did not reach the level of statistical significance $(\mathrm{p}=0.071)$.

Conclusion: PioWJMSCs may produce greater lung regeneration, compared to non-augmented WJMSCs, in a mouse emphysema model.

Keywords: Pioglitazone; Mesenchymal Stem Cells; Emphysema

Address for correspondence: Yeon-Mok Oh, M.D., Ph.D.

Department of Pulmonary and Critical Care Medicine, Asan Medical Center, University of Ulan College of Medicine, 88 Olympic-ro 43-gil, Songpa-gu, Seoul 05505, Korea

Phone: 82-2-3010-3136, Fax: 82-2-3010-4650 E-mail: ymoh55@amc.seoul.kr

* Jin-Soo Park and Hyun Kuk Kim contributed equally to this work.

Received: May. 15, 2018 Revised: Jun. 20, 2018 Accepted: Jul. 17, 2018 Published online: Sep. 28, 2018

@() It is identical to the Creative Commons Attribution Non-Commercial License (http://creativecommons.org/licenses/by-nc/4.0/). 


\section{Introduction}

Chronic obstructive pulmonary disease (COPD) is characterized by irreversible airflow limitation associated with chronic bronchitis and emphysema, and is known as one of the leading causes of death worldwide ${ }^{1-3}$. Although the etiology of COPD remains unclear, there is a clear relationship between smoking and chronic airway inflammation, alveolar destruction by extracellular matrix proteolysis, and ineffective repair of resident lung cells ${ }^{4-7}$. Recent reports describe the effects of stem cell treatments on tissue regeneration in organs like the heart, brain, liver, and lungs ${ }^{8-12}$. Several reports indicated that mesenchymal stem cells (MSCs) from bone marrow had therapeutic effects in an experimental elastaseinduced emphysema model and a cigarette smoke-induced model $^{13-15}$. Other reports examined use of Wharton's Jelly-derived mesenchymal stem cells (WJMSCs) and their potential clinical cell therapy applications in various disease models ${ }^{16-20}$. In this study, we isolated WJMSCs and then examined the effect of WJMSCs injection on two emphysema mouse models, an elastase-induced mouse model and a cigarette smokeinduced mouse model.

Our recent research showed that pioglitazone pretreatment of adipose-derived MSCs increased the production of growth factors, and the resultant therapeutic effects, in an emphysema mouse model, compared to non-treated adiposederived stem cells ${ }^{21}$. We applied this method in an attempt to improve the efficacy of WJMSCs in two emphysema mouse models. Additionally, we sought to identify the distribution of intravenously injected WJMSCs pretreated with pioglitazone (pioWJMSCs), prior to human application.

\section{Materials and Methods}

\section{Cell sources and pretreatment with pioglitazone}

Following the receipt of parental consent, we obtained Wharton's Jelly from the umbilical cord of a baby born at Asan Medical Center in Seoul, Korea. WJMSCs were isolated by the following method. After removal of blood vessels, we dissected the Wharton's jelly, using a scalpel, into small segments. The dissected tissue segments were cultured in a $100-\mathrm{mm}$ cell culture dish with minimum essential medium, alpha modification containing $10 \%$ fetal bovine serum and antibiotics in a humidified $37^{\circ} \mathrm{C}, 5 \% \mathrm{CO}_{2}$ incubator. After 1 week, the cultured tissue segments were treated with $0.05 \%$ trypsin-EDTA (Gibco Life Technologies, Grand Island, NY, USA) and then passed through a $0.45-\mu \mathrm{m}$ cell strainer to obtain WJMSCs. For pioWJMSCs (pioglitazone, Sigma-Aldrich, St. Louis, MO, USA), the WJMSCs culture medium was treated with $3 \mu \mathrm{mol} / \mathrm{L}$ pioglitazone for 1 week.

\section{Mice}

Female C57BL/6 mice, aged 7 weeks, were purchased from Orient Bio (Seongnam, Korea) and maintained under specific pathogen-free conditions in the animal facility of the Institutional Animal Care and Use Committee of Asan Medical Center.

\section{Induction of two mouse emphysema models}

As described previously ${ }^{22}$, we induced an experimental elastase-induced emphysema model by intratracheal injection of $0.6 \mathrm{U}$ of porcine pancreatic elastase (Sigma-Aldrich) at day 0 . The mice were injected with $1 \times 10^{4}$ of pioWJMSC or WJMSC by intravenous injection on day 7 . The animals were killed on day 14 , after which the lungs were removed and prepared for histological analysis.

As described previously ${ }^{14}$, for the experimental smokeinduced emphysema model we exposed mice to cigarette smoke 5 days per week for 6 months using commercially available cigarettes that contained $8.0 \mathrm{mg}$ of tar and $0.6 \mathrm{mg}$ of nicotine (Camel, R. J. Reynolds Tobacco Company, WinstonSalem, NC, USA). After exposure to cigarette smoke for 6 months, the mice were injected with $1 \times 10^{4}$ of pioWJMSCs or WJMSCs by intravenous injection and then killed on day $7 \mathrm{im}$ mediately prior to lung removal and preparation.

\section{Histology and quantification of emphysema}

Lung tissue was inflated with $0.5 \%$ low melting agarose, fixed in $4 \%$ formalin, embedded in paraffin, cut into $6-\mu \mathrm{m}$ thickness, and stained with hematoxylin and eosin. Histological assessment of the sections was determined using the mean linear intercepts (MLI) method ${ }^{23}$.

\section{Fluorescence optical imaging}

For injected pioWJMSC tracking in the lung, we performed fluorescence optical imaging analysis, as described previous$\mathrm{ly}^{24}$. In brief, pioWJMSCs were labeled using the quantum dots (QD) (Q-Tracker 800) Cell Labeling Kit (Invitrogen, Carlsbad, CA, USA). PioWJMSCs $\left(1 \times 10^{6}\right)$ were suspended in $200 \mu \mathrm{L}$ of complete growth medium and labeled with $10 \mathrm{nM}$ of QDs labeling solution. After 60 minutes, QD-labeled cells were washed twice with complete growth medium. We suspended $3 \times 10^{5}$ QDs 800 -labeled pioWJMSCs in $100 \mu \mathrm{L}$ saline and injected into the mice through the tail vain. The mice were sacrificed after 1, 4, 24, and 72 hours and image of the lung was taken using the IVIS Spectrum Pre-clinical In vivo Imaging System (PerkinElmer, Waltham, MA, USA). 


\section{WJMSC tracking using human-specific Alu sequence}

We suspended $3 \times 10^{5}$ pioWJMSCs in $100 \mu \mathrm{L}$ saline, then injected this solution into the mice through the tail vain. The mice were sacrificed after 1, 4, 24, and 72 hours, after which the lungs were removed to extract genomic DNA using a genomic DNA extraction kit (Qiagen, Duesseldorf, Germany). To verify the number of detected lung cells, we performed a standard curve using the pioWJMSCs. A quantitative polymerase chain reaction (qPCR) was carried out as previously described ${ }^{24}$. In brief, polymerase chain reactions (PCRs) were amplified by 40 cycles at $95^{\circ} \mathrm{C}$ for 15 seconds and $70^{\circ} \mathrm{C}$ for 1 minute using the LightCycler 480 SYBR Green I Master (Roche, Mannheim, Germany). PCR was carried out using the LightCycler 480 (Roche) and software. Primer sequences were as follows: Alu, 5'-CGAGGCGGGTGGATCAT-GAGGT-3' and 5'-TCTGTCGCCCAGGCCGGACT-3'.

A

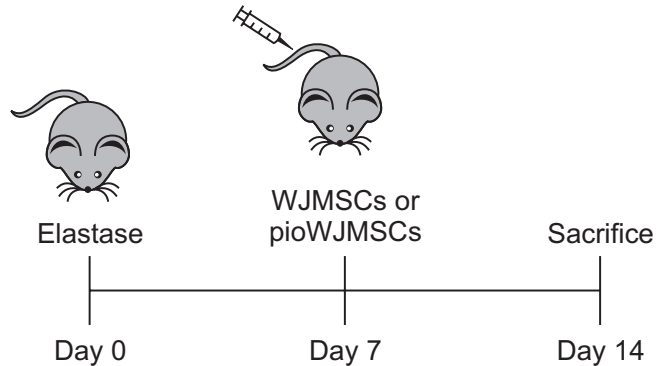

C

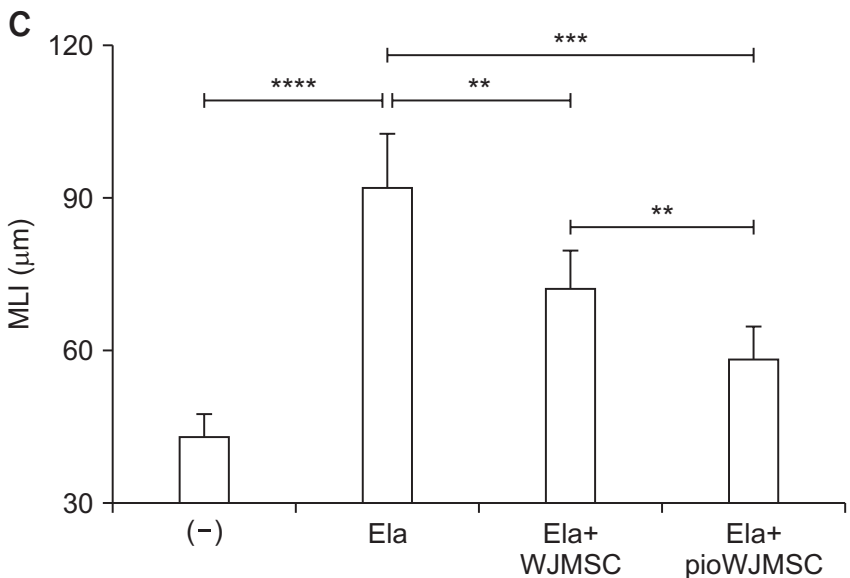

\section{Ethical statement}

This study was approved by the institutional review board of the Asan Medical Center (approval No. 2015-0303). The receipt of parental consent was obtained.

\section{Results}

1. Increased therapeutic effects of pioWJMSCs on lung regeneration in mice with emphysema

\section{1) Elastase-induced emphysema model}

Experimental mice with emphysema are widely used to study COPD and the effects of MSCs. To evaluate the effect of pioWJMSCs, we used an elastase-induced emphysema model with intravenous injection of pioWJMSCs or WJMSCs (Figure 1A). Intratracheal injection of elastase produced severe lung destruction with MLI, an emphysema severity index, increasing from $43.55 \pm 1.9$ to $92.57 \pm 4.56 \mu \mathrm{m}(\mathrm{p}<0.0001)$ (Figure $1 \mathrm{~B}$,

B
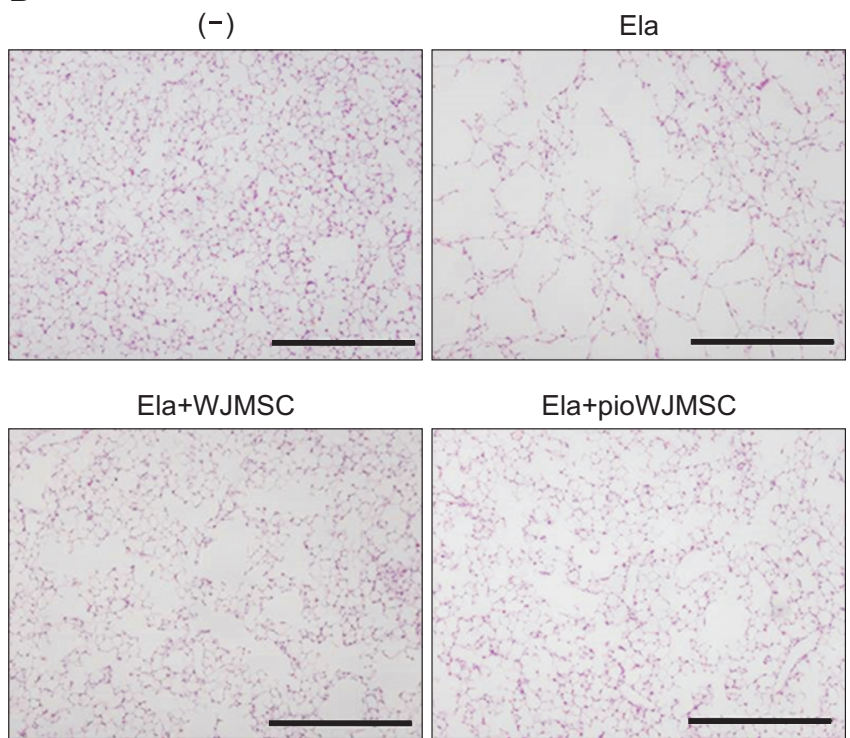

Ela+pioWJMSC

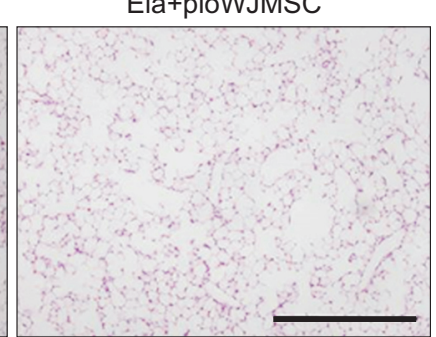

Figure 1. The therapeutic effects of pioglitazone-augmented Wharton's Jelly-derived mesenchymal stem cells (pioWJMSCs) on lung regeneration in mice with elastase-induced emphysema. C57BL/6 mice were intratracheally injected with $0.6 \mathrm{U}$ of elastase (Ela) at day 0 and then intravenously injected with Wharton's Jelly-derived mesenchymal stem cells (WJMSCs) or pioWJMSCs on day 7. (A) Experiment scheme. (B) Hematoxylin and eosin (H\&E) stained lung tissue sections on day 14. (-) control: no elastase; Ela: 0.6 U of elastase; Ela+WJMSC: elastase $+1 \times 10^{4}$ WJMSC; Ela+pioWJMSC: elastase $+1 \times 10^{4}$ pioWJMSC. Scale bars $=0.5 \mathrm{~mm}$. (C) Morphometric analysis of the mean linear intercept (MLI). The values represent the mean \pm standard error of mean $(n=6)$. Statistically significant differences are indicated. ${ }^{* *} \mathrm{p}<0.01,{ }^{* * *} \mathrm{p}<0.001$, **** $\mathrm{p}<0.0001$. 
C). In contrast, both the pioWJMSCs and WJMSCs injection groups exhibited lung regeneration (Figure 1B, C). The mice injected with WJMSCs showed decreased MLI $(72.80 \pm 2.87$ $\mu \mathrm{m})$ and the MLI of pioWJMSCs $(59.02 \pm 2.42 \mu \mathrm{m})$ was significantly decreased, even more than the WJMSCs group $(\mathrm{p}<0.01)$. These results suggested that pioWJMSCs may exhibit augmented regenerative activity in an elastase-induced emphysema model.

\section{2) Cigarette smoke-induced emphysema model}

We observed similar results in the smoke-induced emphysema model (Figure 2A-C). The smoking (SM) group showed lung destruction with MLI increases from $35.43 \pm 0.8$ to $51.65 \pm 1.36 \mu \mathrm{m}(\mathrm{p}<0.0001)$ (Figure $2 \mathrm{~B}, \mathrm{C})$. Both the pioWJMSCs and WJMSCs injected groups showed significantly decreased MLI (WJMSCs $41.25 \pm 0.98 \mu \mathrm{m}$, pioWJMSCs $38.97 \pm 0.61 \mu \mathrm{m} ; \mathrm{p}<0.001)$ compared to the SM group that was not treated, but the difference did not rise to the level of statistical significance $(\mathrm{p}=0.071)$.

A

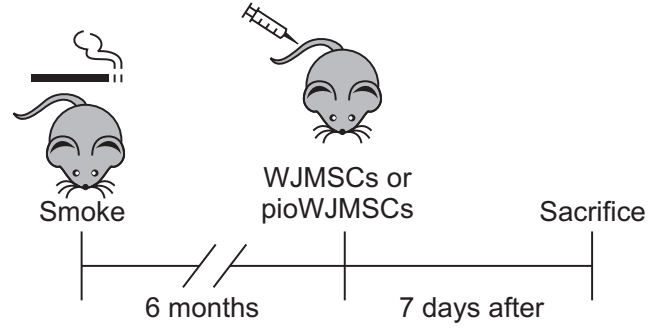

C

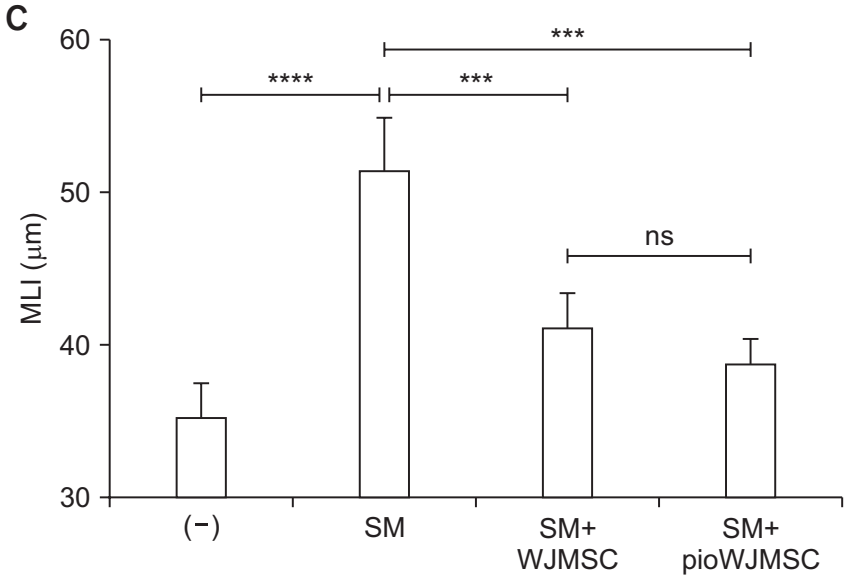

2. Tracking of pioWJMSCs after intravenous injection into the mice

\section{1) QDs-labeled fluorescence image}

To track the distribution of intravenously injected pioWJMSCs in the lung, the pioWJMSCs were labeled with QDs. QDslabeled pioWJMSCs were intravenously injected into the mice, and the fluorescence levels in the lung were analyzed using an optical imaging system at 1, 4, 24, and 72 hours after injection. The fluorescent signal was detected in the lung up to 4 hours (Figure $3 \mathrm{~A}$ ) and gradually decreased as time passed (Figure $3 \mathrm{~B})$. In the control group, the fluorescent signal was undetectable in the lungs at all times. After 72 hours postinjection, we detected no fluorescent signals in the pioWJMSCs group.

\section{2) Tracking using a human-specific Alu sequence}

To quantify the relative amount of intravenously injected pioWJMSCs, we performed qPCR with a human-specific Alu sequence using extracted genomic DNA in pioWJMSCs injected, and non-injected, mice lungs. For analysis using human Alu-specific sequences qPCR data, the regression $\mathrm{r}^{2}$ value curve was determined by $10 \mathrm{ng}$ of genomic DNA from

B
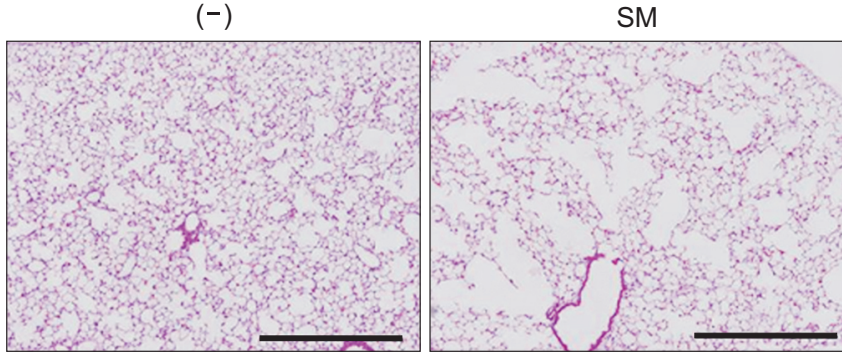

SM+WJMSC

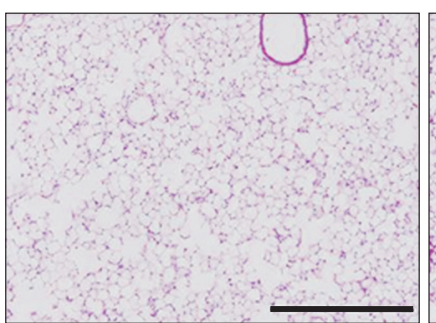

SM+pioWJMSC

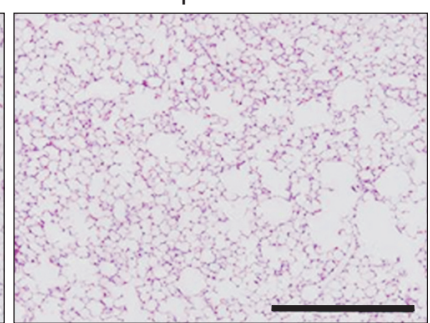

Figure 2. The therapeutic effects of pioglitazone-augmented Wharton's Jelly-derived mesenchymal stem cells (pioWJMSCs) on lung regeneration in mice with smoke-induced emphysema. C57BL/6 mice were exposed to cigarette smoke (SM) for 6 months and then intravenously injected with Wharton's Jelly-derived mesenchymal stem cells (WJMSCs) or pioWJMSCs. (A) Experiment scheme. (B) Hematoxylin and eosin (H\&E) stained lung tissue sections after 7 days of injection. (-) control: no smoke; SM: smoke only; SM+WJMSC: smoke+1 $\times 10^{4}$ WJMSC; SM+pioWJMSC: smoke $+1 \times 10^{4}$ pioWJMSC. Scale bars $=0.5 \mathrm{~mm}$. (C) Morphometric analysis of the mean linear intercept (MLI). The values represent the mean \pm standard error of mean $(n=6)$. Statistically significant differences are indicated. ${ }^{* * *} \mathrm{p}<0.001,{ }^{* * * *} \mathrm{p}<0.0001$. ns, not significant. 
A
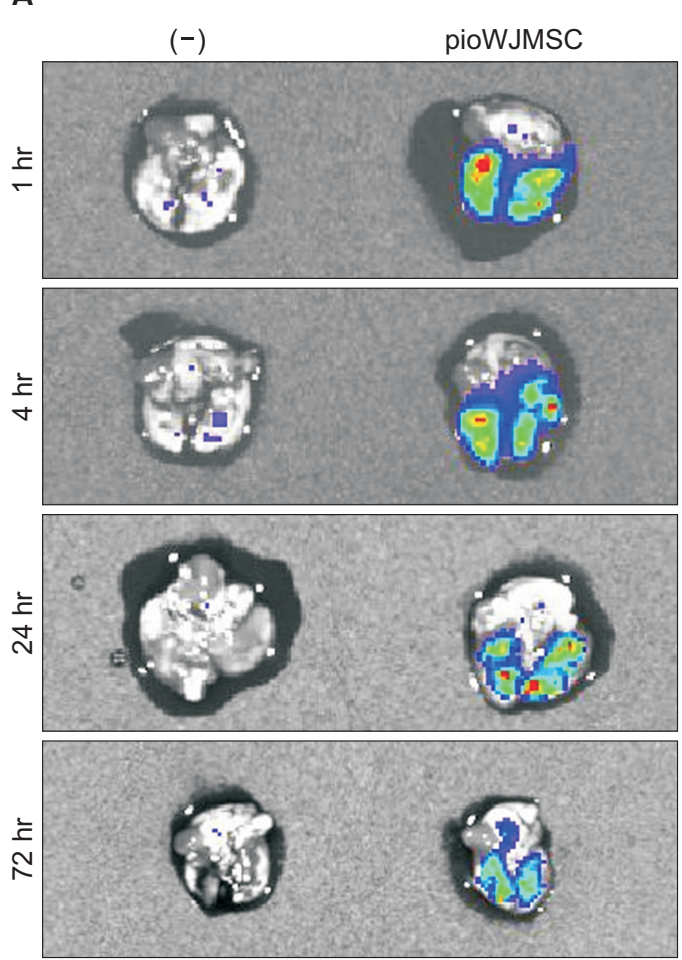

Epi-fluorescence

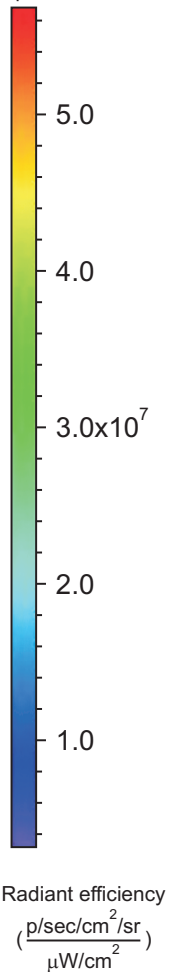

$\left(\frac{\mathrm{p} / \mathrm{sec} / \mathrm{cm}^{2} / \mathrm{s}}{\mu \mathrm{W} / \mathrm{cm}^{2}}\right.$

\section{B}

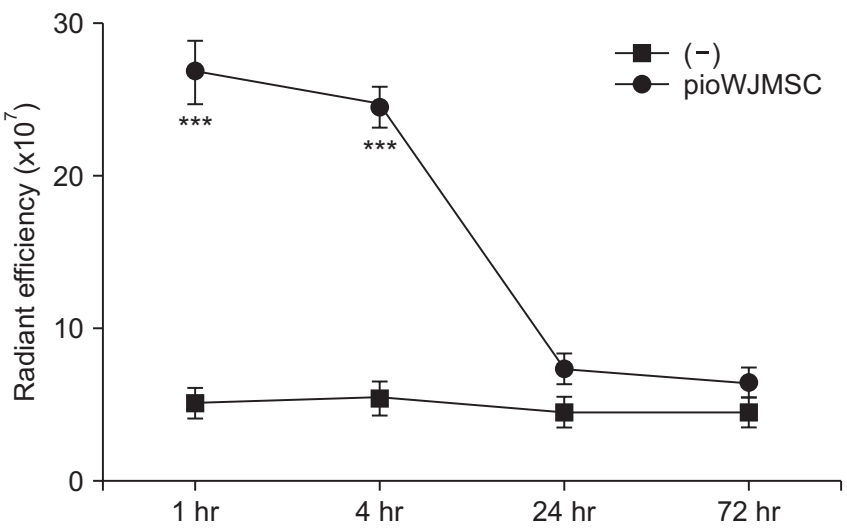

Figure 3. Tracking of pioglitazone-augmented Wharton's Jelly-derived mesenchymal stem cells (pioWJMSCs) after intravenous injection in the lung. (A) The fluorescence images of the lung from (-) control mice or quantum dots (QDs) labeled pioWJMSCs-intravenously injected mice at 1, 4, 24, and 72 hours. Representative images are shown (n=3). (B) Radiant efficiency of the lung from (-) control mice or QDs labeled pioWJMSCs-intravenously injected mice at $1,4,24$, and 72 hours. Statistically significant differences are indicated. ${ }^{* * *} \mathrm{p}<0.001$.

A

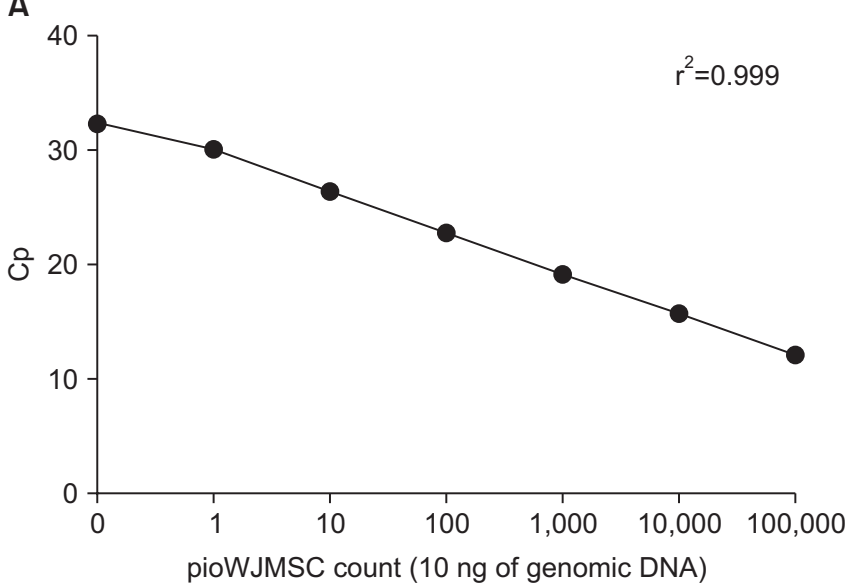

B

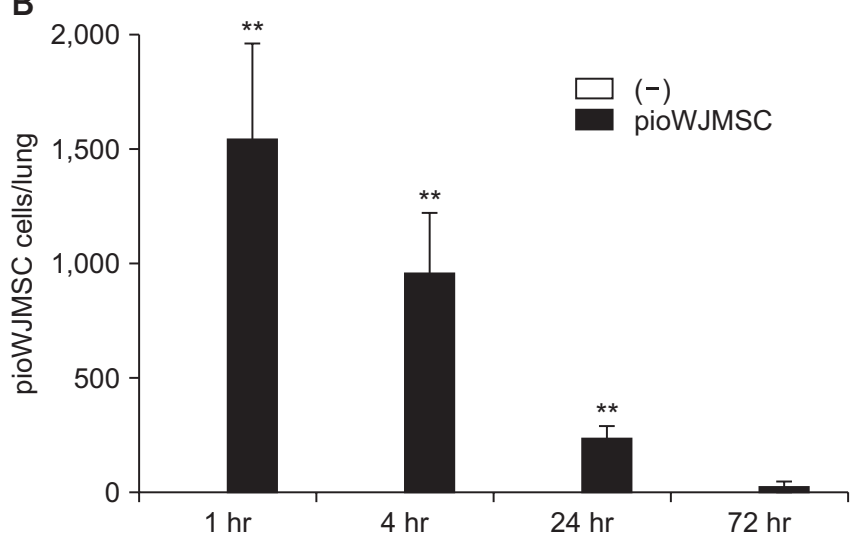

Figure 4. The quantification of the amount of intravenously injected pioglitazone-augmented Wharton's Jelly-derived mesenchymal stem cells (pioWJMSCs) in the lung. (A) Standard curve to evaluate the determination of pioWJMSCs in the lung. (B) The amount of pioWJMSCs in the lung from pioWJMSCs-injected mice or control mice was calculated based on panel A. The values represent the mean \pm standard error of mean $(\mathrm{n}=3)$. Statistically significant differences are indicated. ${ }^{* *} \mathrm{p}<0.01$. 
$10,10^{2}, 10^{3}, 10^{4}$, and $10^{5}$ numbers of pioWJMSCs (Figure 4A). We used this curve as a standard curve for determining the number of intravenously injected pioWJMSCs in the lungs. After injection, there were approximately 1,500 pioWJMSCs at 1 hour, and we continued to detect pioWJMSCs for up to 24 hours in the lung (Figure 4B). PioWJMSCs were undetectable at 72 hours after injection.

\section{Discussion}

In this study, we found that the pioWJMSCs were associated with significantly more lung regeneration in an emphysema mouse model, compared to non-treated WJMSCs. We also examined intravenously injected pioWJMSCs using fluorescence optical imaging and human Alu-specific sequence qPCR for pioWJMSCs tracking in the lung. These data may suggest potential clinical therapeutic effects of pioWJMSCs in COPD.

Previous studies showed that MSCs from other sources like bone marrow have a therapeutic effect in an experimental mouse emphysema model ${ }^{13-15}$. In our recent report, adiposederived stem cells (ASCs) and ASCs-derived nanovesicles exhibit therapeutic lung regeneration effects and increased production of growth factors in mouse models of emphysema ${ }^{21,25}$.

WJMSCs are a source of MSCs for therapeutic applications. The isolation efficiency of WJMSCs ${ }^{26}$ was greater than that of bone marrow ${ }^{27}$ or adipose tissue ${ }^{28}$. WJMSCs also exhibit higher proliferative capacity ${ }^{29}$, abundant production of growth factors $^{30}$, and lack of immunogenicity ${ }^{31,32}$.

In COPD, the regeneration mechanisms of stem cells are not clearly identified; however, several studies have achieved regeneration secondary to the paracrine effects of $\mathrm{MSCs}^{33-35}$, and growth factors such as vascular endothelial growth factor in emphysema mouse models ${ }^{36,37}$. Additionally, fibroblast growth factor-2 enhances stem cell regeneration in canine emphysema models ${ }^{38}$.

There remain disadvantages to stem cell therapy that must be overcome. Bone marrow is best known as a source of MSCs. As donor age increases, the number and proliferative capacity of the stem cells decrease $\mathrm{e}^{39}$. To address this issue, we isolated WJMSCs which are characterized by their ability to differentiate into osteocytes, chondrocytes, and adipocytes ${ }^{40,41}$, better than bone marrow or adipose-derived stem cells within in vitro cultures ${ }^{41}$. WJMSCs are relatively undifferentiated cells, compared to stem cells derived from adipose tissue or bone marrow $^{42}$. WJMSCs also express CD29, CD44, CD73, CD90, and CD105, similar to bone marrow or other tissue-derived mesenchymal stem cells, but the hematopoietic stem cell markers CD34, CD45, and histocompatibility antigen CD14, CD31, and CD33 are not expressed ${ }^{43,44}$. These features may facilitate the use of WJMSCs as cell therapy agents. In this study, we attempted to enhance the efficacy of WJMSCs using piogli- tazone in an emphysema mouse model.

For future clinical trials of pioWJMSCs in COPD patients, we needed to identify the distribution of intravenously injected pioWJMSCs. To accomplish this in mouse lung tissue, we performed fluorescence optical image analysis using a QD labeling kit and human-specific Alu sequence-based qPCR. Using optical imaging, it was easy to track the distribution of QDslabeled cells in tissues. QDs are non-toxic to live cells, have high stability, high fluorescence sensitivity, and possess clinical applications ${ }^{45,46}$. Also, we evaluated the quantity of injected pioWJMSCs in the lung using qPCR with a human-specific Alu primer. Human Alu-sequences are commonly found in introns and present in the human genome at an extremely high copy number $(\sim 500,000 \text { copies })^{47}$. This method is used to detect the human genome in the mouse lung and features highly sensitive, specific, and fast analysis ${ }^{48,49}$.

In conclusion, the results of this study agree with previous findings regarding the regenerative effects of MSCs. pioWJMSCs were more potent, and may serve as a basis for clinical trials with patients in the near future.

\section{Authors' Contributions}

Conceptualization: Oh YM. Methodology: Park JS, Kim HK. Formal analysis: Park JS, Kim HK. Data curation: Park JS, Kang EY, Cho R. Validation: Park JS, Kim HK. Investigation: Park JS, Kang EY, Cho R. Writing - original draft preparation: Park JS. Writing - review and editing: Oh YM. Approval of final manuscript: all authors.

\section{Conflicts of Interest}

No potential conflicts of interest relevant to this article are reported.

\section{Acknowledgments}

The authors thank the members of the Asan Medical Center animal facility and the imaging core lab for their technical expertise. This study was supported by grants from the Korean Health Technology R\&D Project, Ministry of Health \& Welfare, Republic of Korea (no. HI16C2187).

\section{References}

1. Murphy TF, Sethi S. Chronic obstructive pulmonary disease: role of bacteria and guide to antibacterial selection in the older patient. Drugs Aging 2002;19:761-75.

2. Vestbo J, Hurd SS, Agusti AG, Jones PW, Vogelmeier C, An- 
zueto A, et al. Global strategy for the diagnosis, management, and prevention of chronic obstructive pulmonary disease: GOLD executive summary. Am J Respir Crit Care Med 2013;187:347-65.

3. Pauwels RA, Rabe KF. Burden and clinical features of chronic obstructive pulmonary disease (COPD). Lancet 2004;364:613-20.

4. Agusti AG, Noguera A, Sauleda J, Sala E, Pons J, Busquets X. Systemic effects of chronic obstructive pulmonary disease. Eur Respir J 2003;21:347-60.

5. Hogg JC. Pathophysiology of airflow limitation in chronic obstructive pulmonary disease. Lancet 2004;364:709-21.

6. MacNee W, Tuder RM. New paradigms in the pathogenesis of chronic obstructive pulmonary disease I. Proc Am Thorac Soc 2009;6:527-31.

7. Yoshida T, Tuder RM. Pathobiology of cigarette smokeinduced chronic obstructive pulmonary disease. Physiol Rev 2007;87:1047-82

8. Cho GS, Fernandez L, Kwon C. Regenerative medicine for the heart: perspectives on stem-cell therapy. Antioxid Redox Signal 2014;21:2018-31.

9. Donega V, Nijboer CH, van Velthoven CT, Youssef SA, de Bruin A, van Bel F, et al. Assessment of long-term safety and efficacy of intranasal mesenchymal stem cell treatment for neonatal brain injury in the mouse. Pediatr Res 2015;78:5206.

10. Zhao DC, Lei JX, Chen R, Yu WH, Zhang XM, Li SN, et al. Bone marrow-derived mesenchymal stem cells protect against experimental liver fibrosis in rats. World J Gastroenterol 2005; 11:3431-40.

11. Zhu Y, Chen X, Yang X, Ei-Hashash A. Stem cells in lung repair and regeneration: current applications and future promise. J Cell Physiol 2018;233:6414-24.

12. Matthay MA, Goolaerts A, Howard JP, Lee JW. Mesenchymal stem cells for acute lung injury: preclinical evidence. Crit Care Med 2010;38(10 Suppl):S569-73.

13. Longhini-Dos-Santos N, Barbosa-de-Oliveira VA, Kozma RH, Faria CA, Stessuk T, Frei F, et al. Cell therapy with bone marrow mononuclear cells in elastase-induced pulmonary emphysema. Stem Cell Rev 2013;9:210-8.

14. Huh JW, Kim SY, Lee JH, Lee JS, Van Ta Q, Kim M, et al. Bone marrow cells repair cigarette smoke-induced emphysema in rats. Am J Physiol Lung Cell Mol Physiol 2011;301:L255-66.

15. Katsha AM, Ohkouchi S, Xin H, Kanehira M, Sun R, Nukiwa T, et al. Paracrine factors of multipotent stromal cells ameliorate lung injury in an elastase-induced emphysema model. Mol Ther 2011;19:196-203.

16. Kim DW, Staples M, Shinozuka K, Pantcheva P, Kang SD, Borlongan CV. Wharton's jelly-derived mesenchymal stem cells: phenotypic characterization and optimizing their therapeutic potential for clinical applications. Int J Mol Sci 2013;14:11692712.

17. Hammam OA, Elkhafif N, Attia YM, Mansour MT, Elmazar
MM, Abdelsalam RM, et al. Wharton's jelly-derived mesenchymal stem cells combined with praziquantel as a potential therapy for Schistosoma mansoni-induced liver fibrosis. Sci Rep 2016;6:21005.

18. Tamura M, Kawabata A, Ohta N, Uppalapati L, Becker KG, Troyer D. Wharton's jelly stem cells as agents for cancer therapy. Open Tissue Eng Regen Med J 201 1;4:39-47.

19. Scheers I, Lombard C, Najimi M, Sokal EM. Cell therapy for the treatment of metabolic liver disease: an update on the umbilical cord derived stem cells candidates. Open Tissue Eng Regen Med J 2011;4:48-53.

20. Rachakatla RS, Marini F, Weiss ML, Tamura M, Troyer D. Development of human umbilical cord matrix stem cell-based gene therapy for experimental lung tumors. Cancer Gene Ther 2007;14:828-35.

21. Hong Y, Kim YS, Hong SH, Oh YM. Therapeutic effects of adipose-derived stem cells pretreated with pioglitazone in an emphysema mouse model. Exp Mol Med 2016;48:e266.

22. Kim YS, Kim JY, Huh JW, Lee SW, Choi SJ, Oh YM. The therapeutic effects of optimal dose of mesenchymal stem cells in a murine model of an elastase induced-emphysema. Tuberc Respir Dis 2015;78:239-45.

23. Thurlbeck WM. Measurement of pulmonary emphysema. Am Rev Respir Dis 1967;95:752-64.

24. Kim YS, Kim JY, Shin DM, Huh JW, Lee SW, Oh YM. Tracking intravenous adipose-derived mesenchymal stem cells in a model of elastase-induced emphysema. Tuberc Respir Dis 2014;77:116-23.

25. Kim YS, Kim JY, Cho R, Shin DM, Lee SW, Oh YM. Adipose stem cell-derived nanovesicles inhibit emphysema primarily via an FGF2-dependent pathway. Exp Mol Med 2017;49:e284.

26. Weiss ML, Medicetty S, Bledsoe AR, Rachakatla RS, Choi M, Merchav S, et al. Human umbilical cord matrix stem cells: preliminary characterization and effect of transplantation in a rodent model of Parkinson's disease. Stem Cells 2006;24:78192.

27. Pittenger MF, Mackay AM, Beck SC, Jaiswal RK, Douglas R, Mosca JD, et al. Multilineage potential of adult human mesenchymal stem cells. Science 1999;284:143-7.

28. Fraser JK, Wulur I, Alfonso Z, Hedrick MH. Fat tissue: an underappreciated source of stem cells for biotechnology. Trends Biotechnol 2006;24:150-4.

29. Amable PR, Teixeira MV, Carias RB, Granjeiro JM, Borojevic R. Protein synthesis and secretion in human mesenchymal cells derived from bone marrow, adipose tissue and Wharton's jelly. Stem Cell Res Ther 2014;5:53.

30. Yoon JH, Roh EY, Shin S, Jung NH, Song EY, Chang JY, et al. Comparison of explant-derived and enzymatic digestionderived MSCs and the growth factors from Wharton's jelly. Biomed Res Int 2013;2013:428726.

31. Weiss ML, Anderson C, Medicetty S, Seshareddy KB, Weiss RJ, VanderWerff I, et al. Immune properties of human umbilical cord Wharton's jelly-derived cells. Stem Cells 2008;26:2865- 
74.

32. Jyothi Prasanna S, Sowmya Jahnavi V. Wharton's jelly mesenchymal stem cells as off-the-shelf cellular therapeutics: a closer look into their regenerative and immunomodulatory properties. Open Tissue Eng Regen Med J 2011;4:28-38.

33. Hackett TL, Knight DA, Sin DD. Potential role of stem cells in management of COPD. Int J Chron Obstruct Pulmon Dis 2010;5:81-8.

34. Yoshida H, Kitaichi T, Urata M, Kurobe H, Kanbara T, Motoki T, et al. Syngeneic bone marrow mononuclear cells improve pulmonary arterial hypertension through vascular endothelial growth factor upregulation. Ann Thorac Surg 2009;88:41824.

35. Murphy MB, Moncivais K, Caplan AI. Mesenchymal stem cells: environmentally responsive therapeutics for regenerative medicine. Exp Mol Med 2013;45:e54.

36. Muyal JP, Muyal V, Kotnala S, Kumar D, Bhardwaj H. Therapeutic potential of growth factors in pulmonary emphysematous condition. Lung 2013;191:147-63.

37. Guan XJ, Song L, Han FF, Cui ZL, Chen X, Guo XJ, et al. Mesenchymal stem cells protect cigarette smoke-damaged lung and pulmonary function partly via VEGF-VEGF receptors. J Cell Biochem 2013;114:323-35.

38. Morino S, Nakamura T, Toba T, Takahashi M, Kushibiki T, Tabata Y, et al. Fibroblast growth factor-2 induces recovery of pulmonary blood flow in canine emphysema models. Chest 2005;128:920-6.

39. Stenderup K, Justesen J, Clausen C, Kassem M. Aging is associated with decreased maximal life span and accelerated senescence of bone marrow stromal cells. Bone 2003;33:91926.

40. Romanov YA, Svintsitskaya VA, Smirnov VN. Searching for alternative sources of postnatal human mesenchymal stem cells: candidate MSC-like cells from umbilical cord. Stem Cells 2003;21:105-10.

41. Karahuseyinoglu S, Cinar O, Kilic E, Kara F, Akay GG, Demiralp DO, et al. Biology of stem cells in human umbilical cord stroma: in situ and in vitro surveys. Stem Cells 2007;25:31931.

42. Carlin R, Davis D, Weiss M, Schultz B, Troyer D. Expression of early transcription factors Oct-4, Sox-2 and Nanog by porcine umbilical cord (PUC) matrix cells. Reprod Biol Endocrinol 2006;4:8.

43. Choudhery MS, Badowski M, Muise A, Harris DT. Comparison of human mesenchymal stem cells derived from adipose and cord tissue. Cytotherapy 2013;15:330-43.

44. Wang HS, Hung SC, Peng ST, Huang CC, Wei HM, Guo YJ, et al. Mesenchymal stem cells in the Wharton's jelly of the human umbilical cord. Stem Cells 2004;22:1330-7.

45. Yukawa H, Mizufune S, Mamori C, Kagami Y, Oishi K, Kaji N, et al. Quantum dots for labeling adipose tissue-derived stem cells. Cell Transplant 2009;18:591-9.

46. Yukawa H, Watanabe M, Kaji N, Okamoto Y, Tokeshi M, Miyamoto $\mathrm{Y}$, et al. Monitoring transplanted adipose tissue-derived stem cells combined with heparin in the liver by fluorescence imaging using quantum dots. Biomaterials 2012;33:2177-86.

47. Batzer MA, Deininger PL. Alu repeats and human genomic diversity. Nat Rev Genet 2002;3:370-9.

48. Nicklas JA, Buel E. Development of an Alu-based, real-time PCR method for quantitation of human DNA in forensic samples. J Forensic Sci 2003;48:936-44.

49. Batzer MA, Gudi VA, Mena JC, Foltz DW, Herrera RJ, Deininger PL. Amplification dynamics of human-specific (HS) Alu family members. Nucleic Acids Res 1991;19:361923. 